Fecha de recepción: febrero 2019 Fecha de aceptación: marzo 2019 Versión final: mayo 2019

\section{Las Quintralas audiovisuales, Melodrama, época, romance y el diablo}

Claudia Bossay *

Resumen: Este artículo analiza cómo se ha representado a la mujer de la colonia, específicamente tomando en cuenta el caso de Catalina de los Ríos y Lisperberg personaje histórico real, convertido en el mito arquetípico de la mujer monstruo bajo el sobrenombre de la Quintrala. Se analizará la película argentina La Quintrala (1955) dirigida por Hugo del Carril. La miniserie de televisión de Vicente Sabatini, La Quintrala, exhibida en Televisión Nacional de Chile (TVN) y emitida entre abril y julio de 1987, en plena dictadura. El capítulo "El mestizaje, la Quintrala y el poder de los jesuitas (1557 - 1721)" de Algo habrán hecho por la historia de Chile, dirigido por Nicolás Acuña, estrenada en TVN en junio 2010 y La Doña, telenovela nocturna también de Sabatini, estrenada en el canal de televisión abierta Chilevisión, en octubre de 2011. A través de estas representaciones evaluaremos como se imaginó el pasado y a la mujer en cada caso, proponiendo una nueva interpretación de Catalina.

Palabras clave: representación audiovisual - mujer-monstruo - colonia chilena

[Resúmenes en inglés y portugués en la página 37]

(*) Profesora asistente y académica del Instituto de la Comunicación e Imagen de la Universidad de Chile (ICEI) y Doctora en Estudios de Cine por la Queen's University Belfast, Reino Unido. Sus áreas de especialización trabajan interdiciplinariamente la historia desde el cine, estudiando la representación de la historia en el audiovisual, ya sea ficción, documental o experimental, cine o televisión. Actualmente su investigacion se enfoca en los estudios de audiencias históricas de cine en Chile, mediante un fondo PAI79170064, de CONICYT "Cartelera histórica. Estudio de exhibición y recepción de cine en Santiago entre 1918 y 1969."

Catalina de los Ríos y Lisperberg, más conocida como la Quintrala, fue un personaje real de la primera mitad del siglo XVII, durante la colonia chilena, quien, por su forma de ser, pasó a los anales de la historia enredada en mitos y supersticiones, juicios y prejuicios. Reducida a bruja, temida por sus tratos con el diablo, quien a todas luces le ha de haber dado su poder. Porque, ¿de qué otro modo podría una mujer haber logrado tal nivel de riquezas, influencia e independencia? Convertida en mujer-monstruo, arquetipo universal de 
la mala mujer "desprovista de humanidad y poseedora de terribles poderes." (Suazo, 2018, p.123), la asesina en serie con poder, que ejerce lo prohibido: "parricidio, incesto, adulterio, tortura y homicidio" (Sarabia, 2000, p. 38). No es de sorprender que, como parte del folklore popular, este personaje llegase a la televisión chilena en forma de ficción al menos en tres ocasiones distintas: La Quintrala, miniserie de ocho episodios dirigida por Vicente Sabatini (TVN, exhibida entre abril y julio de 1987); el episodio "El mestizaje, la Quintrala y el poder de los jesuitas (1557 - 1721)" de la serie educativa Algo habrán hecho por la historia de Chile, dirigida por Nicolás Acuña (TVN, 2010); y la teleserie nocturna La Doña, de 92 episodios estrenados entre el 4 de octubre del 2011 y el 4 de abril del 2012, dirigida por Vicente Sabatini y Mauricio Bustos (Chilevisión). Quizás un poco más sorprendente es que también haya llegado a la pantalla grande en Argentina, a través de una película dirigida por el reconocido y multifacético artista, Hugo del Carril (1955). Basándonos en las representaciones de este controversial personaje, evaluaremos cómo han sido imaginadas cada una de estas protagonistas, explorando los límites de los géneros audiovisuales de cada obra, y la representación que hizo cada período histórico sobre este lejano pasado y las mujeres que lo habitan ${ }^{1}$.

\section{La Quintrala cinematográfica}

"una rara avis de nuestro cine, un verdadero trabajo de orfebrería cinematográfica, estremecedora hasta lo impredecible, agobiante hasta la asfixia en el retrato físico y cruel, de un pasado virreinal, escabroso, nocturnal, sórdido y amenazante (Cabrera 1989, p. 119).

Esta Quintrala de la gran pantalla fue personificada por Ana María Lynch, una bellísima actriz argentina que había conocido al director de la película años antes trabajando como extra en otra obra, y tras lo cual establecieron una larga relación amorosa. Si bien para el momento de la preproducción de La Quintrala, ya no estaban juntos, Lynch no dudó en invitar a del Carril a la dirección de la obra. Este es un punto importantísimo, ya que fue ella quien consiguió los elevados fondos para rodar esta cinta y en primera instancia liderar "este emprendimiento" (Paladino 2006, p.75)². Los créditos de la obra, sin embargo, solo presentan la cinta como una producción de Hugo del Carril.

Esta obra contó con cuatro millones de pesos de presupuesto, algo que diversos historiadores han sostenido que era poco común para el cine argentino de la década de $1950^{3}$. Para algunas de las escenas más complejas, se contrataron hasta cien extras, a quienes se les maquilló y vistió a usanza de la época. Los actores y actrices que acompañan a Lynch en escena eran figuras destacadas y reconocidas del cine argentino e internacional, particularmente el coprotagonista Fray Pedro de Figueroa, interpretado por el popular actor portugués Antonio Vilar, quien ayudaba a consolidar así las posibilidades de éxito internacional de la obra ${ }^{4}$. Conjunto con esto, la película fue filmada en widescreen por Pablo Taberno quien además llevó a cabo una compleja iluminación de claro oscuros y fotografía de contrapicados, con extensas secuencias nocturnas y potentes detalles de primerísimos primeros planos de la protagonista y sus poderosa mirada. Incluso más, el mismísimo 
director organizaba sonido direccional para las escasas exhibiciones que se alcanzaron a realizar en el Teatro Ópera-antes de ser sacada de cartelera- y en la escena del terremoto subía el volumen desde la cabina de exhibición (Cabrera 1989, p.69). Estos elementos demuestran un deseo de hacer de esta obra un gran desplante de capacidades técnicas y estéticas, de demostrar todo el potencial industrial del cine argentino en una obra histórica. Como sugiere Cabrera, La Quintrala "significó un esfuerzo de producción pocas veces igualado en nuestro cine, y el rodaje más complejo de los que encarara del Carril" (Cabrera 1989, p. 93). Sin embargo, todos estos esfuerzos y el arduo trabajo se verían frustrados por las complejidades del presente argentino, la censura imperante y la por venir.

El director Hugo del Carril fue un multifacético ídolo popular conocido como "Hugo del pueblo" (Calzón 2016, p. 13). Luego de haber adquirido fama en España y Latinoamérica, y de haber residido en México por algunos años, del Carril vuelve a Argentina y comienza su carrera de director de cine, en dónde pasa a tratar temáticas de denuncia y crítica social, defendiendo al pueblo, es decir, a quienes le dieran su fama en primer lugar en sus años de cantante popular ${ }^{5}$. Tras el éxito de público y crítica de Las aguas bajan turbias (1952), las relaciones con el gobierno peronista y en particular con el Secretario de Prensa y Difusión, Raúl Apold, se tensionan tras ser acusado "de simpatizar con ideologías de izquierda por la adaptación de la novela de un comunista, Alfredo Varela, como base argumental de su película" (Calzón 2016, p. 2). Pese a que del Carril fue un acérrimo peronista, en este período el Estado ejerció una censura informal cuyo motor no era exclusivamente ideológico o sobre la imagen de Argentina, sino también por enemistades o roces entre funcionarios del gobierno y los artistas (Kelly, 2009, Kriger, 2009). En La Quintrala podemos ver un buen ejemplo de dichos problemas.

Esta película comenzó su producción en 1953, pero estuvo sometida a una suspensión de seis meses debido a unos comentarios de del Carril sobre la falta de apoyo del Estado para ir al Festival de Venecia con su película anterior, y la contraacusación de Apold de que del Carril había cantado en una radio uruguaya el día de la muerte de Evita (Maranghello 1993, p. 11) ${ }^{6}$. Finalmente, en un total de cuatro meses de producción real, la obra estuvo lista para su exhibición en junio del 1954. A finales de agosto de este mismo año tuvo su estreno internacional en el festival de Venecia, fuera de la competencia, y a finales del mismo año, la película se exhibe para la Asociación de Cronistas Cinematográficos Argentinos, en el Ópera ${ }^{7}$. Lo que ayudó a que la película fuese comentada en prensa, pese a no ser aun exhibida al público general. El estreno se pospuso varias veces y finalmente fue estrenada comercialmente casi un año después de estar lista, el 26 de mayo de $1955^{8}$. Pareciera que los retrasos de producción y exhibición se pueden a tribuir a que Apold estimaba que la crítica de la película hacia la iglesia católica podía ser malinterpretada por los católicos quienes ya entraban en una escalante tensión con el gobierno, lo que llevó también a que la película se bajara de cartelera (Calzón 2016, p. 15).

Aún más, a partir del golpe militar del 16 de septiembre de 1955, conocido como la Revolución Libertadora, el peronismo es proscrito y Hugo del Carril es llevado preso, Lynch también ingresa a la lista negra de artistas peronistas, la película es retirada de cartelera y se prohíben otras obras del autor. Desde el 24 de octubre del mismo año, del Carril es detenido bajo la acusación de malversación de fondos del estado, específicamente por el traslado internacional de sus películas sin pago de impuestos (Maranghello 1993, p. 12). 
Tras estar más de cuarenta días preso es liberado y exonerado, más ha de esperar algunos meses más para que la película vuelva a cartelera, para cuando ya se había dañado su "repercusión popular” (Cabrera 1989, p. 70). Sus películas y espectáculos seguirían siendo, en mayor o menor medida, censurados hasta 1970.

Para Ana Laura Lusnich, del Carril usa las convenciones del melodrama en su cine como una extensión de su escritura propia, lo que ayuda a hacerlo un cine de autor (En Maranghello 1923, p. 23). Maranghello describe esta obra como un drama histórico, uno de los seis subgéneros de la obra de del Carril (Maranghello, 1993, p.17). La Quintrala fusiona el melodrama de autor con el drama histórico creando una obra romántica y de época, "arte llevado a su cima en manos de la crueldad de la Quintrala" (Cabrera 1989, p. 119). El guión de Eduardo Borras estuvo basado en las obras del historiador Benjamin Vicuña Mackenna y la novela de Magdalena Petit ${ }^{9}$. Además, contó con el chileno Jorge Inostroza, como asesor histórico de reconocida carrera en cine y teatro. Del Carril defiende este cambio de género y de temática, de país y período histórico diciendo "Pienso que la versatilidad de temas es necesaria, un director de cine debe encarar otros géneros” (Cabrera 1989, p. 67).

\section{La Quintrala en dictadura}

Esta Quintrala fue protagonizada por Raquel Argandoña. Para 1987, año de estreno, era uno de los rostros fuerza de las pantallas de TVN, tras haber sido Miss Chile en 1975, representado al país en un certamen internacional de belleza y haber leído por varios años las noticias en 60 minutos (1975-1988, TVN) el noticiero central del canal oficialista de la dictadura ${ }^{10}$. Entra trabajar en la televisión a sus 14 años (1971), a través de una breve colaboración en el programa de baile Tip-Top, del cual se va tan solo unas semanas más tarde, para comenzar a trabajar en Sábado gigante (1962-2015, Canal 13, Univisión), el famoso programa ómnibus de Canal 13, del cual se retiró tras un conflicto con su animador Don Francisco (Mario Kreutzberger). La modelo, animadora, conductora y actualmente panelista de matinales y programas de farándula chilena, suma más de treinta años en la pantalla y un sinnúmero de rivalidades con personajes públicos. El papel de la Quintrala fue el más importante como actriz -también trabajó brevemente para Televisa en México-. La fuerza del personaje la ayudó a inmortalizarse en la televisión ${ }^{11}$. Argandoña es parte de la historia de la televisión de Chile, por haber interpretado a la Quintrala, pero también por ser parte de la oficialidad visual de la dictadura ${ }^{12}$.

El director de esta miniserie, Vicente Sabatini, creció en una familia relacionada con el arte, con tíos como el artista visual Juan Downey (1940-1993) y el cineasta Patricio Kaulen (1921-1999). Pese a haber trabajado en continuidad y haber sido asistente de dirección en algunos programas de Canal 9, su carrera toma un vuelco cuando es contratado por la destacada directora ejecutiva del Área Dramática de Televisión Nacional, Sonia Füchs, quien conociera a Sabatini desde sus años universitarios, dónde ella fue su profesora en la EAC (Escuela de Artes de la Comunicación- Pontificia Universidad Católica de Chile) y que fuera la productora ejecutiva de La Quintrala. En TVN, Sabattini ayudó a consolidar el área dramática, con obras como la aquí explorada, para luego en la década de 1990, pa- 
sar a ser el director del área y consolidar la llamada "época de oro de las teleseries", en las cuales primaba un fuerte contenido social, con locaciones descentralizadas de Santiago, y con temáticas culturales, históricas y de contingencia. La Quintrala, fue un antecedente a estos tópicos y también al éxito de sus creaciones.

La dirección de actores de esta miniserie estuvo a cargo de la reconocida actriz Ana Reeves, quien retornaba de tu autoexilio en 1982 y tras trabajar en Canal 13, pasa a TVN donde se queda por más de 28 años. Trabajó como actriz, escribió escenas, hizo clases a actores y los dirigió (Fundación Getionarte, 2018, 142). Reeves comenta en una entrevista sobre la dificultad que tuvo al dirigir a Argandoña, "no le podía enseñar lo que no podía hacer" mas sugiere que cómo Argandoña era diciplinada y rigurosa, fue posible ser guiada de cerca para llevar a puerto el personaje (Mentiras verdaderas, 2014). Efectivamente, el personaje no es un desborde de talento actoral, más pareciera que por la personalidad de la propia Argandoña, el rol de Quintrala le calzó. Dado su belleza y confrontacional personalidad, el sobrenombre de la Quintrala se le adhirió a Argandoña, que incluso hoy es referida como el papel que interpretó hace más de treinta años. Tanto es así, que en un programa de fenómenos paranormales, La Hermandad (Chilevisión, 2017) ${ }^{13}$ ante el esfuerzo de imaginar el personaje real -la serie utiliza las imágenes de la película de del Carril- un panelista de sugiere que el siente que el personaje histórico se veía como Argandoña, a lo que otro panelista responde "todo Chile la asocia" e incluso más, uno de ellos pregunta “¿No será la reencarnación” otro responde "No, porque la Raquel es buena persona y la Quintrala no." Demostrando la valoración, tanto en el mito como en la interpretación de la Argandoña, de la mujer fuerte, sin pelos en la lengua, violenta, pero que cree que su accionar está en lo correcto.

\section{La quintrala nocturna}

Cuando Sabatini deja el área de dirección de TVN y migra al canal Chilevisión en el 2010, se lleva consigo parte del equipo técnico del canal nacional, además de algunas ideas, quizás el caso más evidente la teleserie nocturna La Doña (2011), serie que seguía las andanzas de la Quintrala, pero con la posibilidad de explorar la sexualidad con la libertad que brinda el horario nocturno. Esta sexualizada Quintrala estuvo protagonizada por Claudia Di Girólamo, una reconocida actriz de teleseries, con decenas de protagónicos en el cuerpo, además de una carrera de dramaturgia y teatro. Parte de lo que debe haber hecho posible que esta gran estrella trabajara en la nueva área dramática de un canal, y en un proyecto nocturno en vez de en horario prime, es que es la esposa del director y migró junto con él a Chilevisión -así como tantos otros-. En esta época altamente dependiente del ratting, La Doña no tuvo el éxito que esperaba la estación y comenzaron los rumores del cierre del área, lo que finalmente sucedería cuatro años más tarde ${ }^{14}$. Esta teleserie contó con 92 capítulos, y fue la más cara que realizó el canal (3 millones de dólares). Aun así, solo los exteriores -que son bastantes para una teleserie de este tipo- se filmaron en HD, los interiores están en SD y con cinta de enmascarar negras arriba abajo, para generar el efecto widescreen. 
La Doña tuvo por tema principal una canción compuesta por Raúl Alarcón un reconocido, transgresor y provocador músico chileno ${ }^{15}$. Su carrera musical ha estado estrechamente relacionada con la televisión, en tanto trabajó en la orquesta del programa Sábado gigante y representó a Chile en el Festival de la canción de Viña del Mar (1977, donde interpreta por primera vez al personaje de Florcita Motuda) y en el Festival de la OTI (1978, 1981 y 1998). Además de músico, siempre tuvo una participación política activa representando al partido Humanista ${ }^{16}$. Ocupó su rol de figura pública para desafiar a la dictadura, así como para apoyar la campaña del No, para el plebiscito de 1989.

Su música tiene un elemento de crítica social, fusionando su pensamiento político, arte experimental y conocimiento sobre la televisión. Es sátira y es llamado a la subversión. Alrededor del año 1978, Florcita Motuda compone Circulación primaveral del sexo, o Quintralada, para presentarla en el programa Lunes de Gala (Canal 13, 1979) ${ }^{17}$ que conducía Cesar Antonio Santis. Esta canción es un temprano exponente de las cuecas eróticas que ha compuesto a través de su carrera. Además, tenía como interpretes tanto a Florcita como a Patricia Maldonado, una cantante de potente voz que es abierta defensora de Pinochet, tanto en 1978 como en nuestros días. Hoy la podemos escuchar como comentarista de diversos programas de farándula, y mantiene una amistad fuerte con Raquel Argandoña como mujeres fuertes deslenguadas, y defensoras del dictador.

La lección de esta co-intérprete no ha de sorprender. Florcita expresa tras la presentación final de la pieza que "La canción es una fantasía tomando como estímulo el personaje de la Quintrala”. Una mujer que en la mitología popular siempre ha sido muy fuerte. Más agrega, que en verdad es una canción sobre el despertar del deseo sexual de una mujer, y que su personaje, una especie de filósofo campesino, le explica a la mujer lo que le sucede. Florcita viste de huaso tradicional chileno, baila cueca, y se saca el sombrero cuando canta acerca del sexo. Maldonado está vestida con pantalones negros y una blusa y chaqueta blanca de lentejuelas que es un leve guiño a la vestimenta de la huasa elegante. Es una invitación a la clase alta a participar de los conocimientos del pueblo, es una invitación a la libertad.

Acompañada de una gran instrumentalización a cargo del Maestro Juan Salazar, Maldonado entra a la pieza cantando "Se escuchan ardientes los resoplidos, de una, de una hembra tan engrifada." Parte del feminismo reivindicativo de esta canción está precisamente asociado a elección de la Maldonado. Su imponente voz y su evidente influencia mediática, la hacían uno de los rostros femeninos de la dictadura. Florcita ha descrito que para él la hembra engrifada es una "fusión del sexo femenino y masculino", es decir una actitud que reúne rasgos femeninos tradicionales con otros generalmente atribuidos al hombre, pero en estas hembras se fusionan y ya no cumplen el estereotipo de género binario. "Entre tierna y firme" (Musicapopular.cl) suma Florcita, una mujer empoderada, que sabe lo que quiere y no teme a ser cariñosa y mostrarse vulnerable, ya que no le resta poder. Cuando César Antonio Santis le pregunta a Maldonado cómo se dio la colaboración con Florcita ante las risas del público por lo inusual de la pareja- ella sencillamente respondió que pese a que no es su línea "le dio algo rico de adentro" y por eso la interpretó. De este material es posible analizar que para Maldonado la oposición ideológica entre ella y el músico, no iban más allá del potencial liberador y empoderado de la canción.

Aún más, esta canción comienza con un llamado al levantamiento "Arriba, arriba las desatadas. Abajo, abajo las reprimidas." Se agrega más tarde "Déjala que se mueva desnuda si 
lo prefiere, déjala que libere bailando, su pensamiento, a ver si así revienta el silencio que le vigila." De este modo la canción es un claro llamado a la subversión contra el ojo vigilante de la dictadura. Proclama libertad, desnudez, música, liberación e incluso voz. Al final de la breve entrevista entre animador e intérpretes y cuando ya se habían despedido, Florcita vuelve a tomar el micrófono y dice que esta pieza es "en parte un punto de vista y en parte un juego..." Con un tono irónico añade "y hemos jugado muy bien." Sumando así, una subversión a la dictadura a la revolución con respecto al sexo. Esta canción no fue incluida en la versión de la dictadura de La Quintrala, siendo que por años podría haber sucedido, pero lo más probable es que por ideología y conservadurismo no fue posible, pero sí es la pieza principal en $L a$ Doña, aunque interpretada por María Jimena Pereyra, cantante argentina radicada en Chile.

\section{La Quintrala educacional}

Finalmente, la cuarta Quintrala audiovisual es parte del programa Algo habrán hecho por la historia de Chile, una versión local del programa Algo habrán hecho por la historia de Argentina (Canal Trece, 2005 Telefe, 2006- 2008) producido por la productora independiente Eyeworks Cuatro Cabezas. La idea fue traída a Chile a través de TVN, que tras el programa Grandes chilenos (TVN, 2008) recibió duras críticas acerca de lo poco que parecía conocer la población chilena su historia más antigua. Así, también producida por Eyeworks Cuatro Cabezas en co-producción con Promocine y TVN, la versión chilena del programa histórico-cultural argentino se realizó durante el año 2010. La dirección estuvo a cargo de Nicolás Acuña y la conducción fue liderada por el reconocido actor Francisco Melo y el historiador Manuel Vicuña. Con sólo una temporada de ocho capítulos, que llegan hasta la celebración del centenario, los cuatro primeros se refieren al proceso de la colonia y la independencia de Chile, el segundo episodio titulado "El mestizaje, la Quintrala y el poder de los jesuitas (1598 - 1721)" fue estrenado el 25 de julio de 2010.

Este episodio se centra fuertemente en el rol de las mujeres en el período. Habla de las mujeres españolas tomadas como botines de guerra en la revolución del sur del país y los niños mestizos, habla de las monjas que lograban obtener cierta independencia intelectual $-y$ económica- dentro de diversas órdenes, así como el particular caso de la terrateniente más famosa de la historia de Chile. La Quintrala está interpretada por la actriz Begoña Basauri -quien por el mismo tiempo comenzaba a protagonizar otras series de televisión-. La actriz comentó en una entrevista que le "da nervio" interpretar un papel que "tiene que ver con lo oscuro". Mas agregó que cómo el personaje pasó a la historia "tiene más que ver con que sea mujer y con el poder que tenía" (Letelier, 2010). Esto es profundizado por el historiador Manuel Vicuña, quien explica que pocas mujeres tienen acceso al poder, excepciones son algunas viudas de buena situación o la misma Catalina de los Ríos y Lisperberg. Su mala fama es el alto precio que pagó por tener poder e independencia en esta época. Ella desafió a los estereotipos de la época. Fue mestiza, con parientes indígenas, españoles, alemanes y además tenía un gran conocimiento sobre ritos afroamericanos e indígenas. Convertir todo esto en su desventaja fue "la mejor manera de anularla", según el historiador/presentador. El historiador contemporáneo agrega que trataba tan mal a sus trabajadores como cualquier 
hombre de la época y que más bien el mito del monstro de la Quintrala viene de los escritos de Benjamín Vicuña Mackenna, 200 años después de la vida del personaje histórico. Suazo suma que para Vicuña Mackenna lo verdaderamente monstruoso de Catalina, era que tenía sangre indígena, claro, sumado a ser mujer (2018, p.135).

Nicolás Acuña comenta que para el casting de esta versión, desmitificada y con agencia de la Quintrala, debieron buscar a una mujer que se le pareciera lo menos posible a Raquel Argandoña, pero que aún mantuviese el mito de la belleza: pelo colorín, ojos claros, alta impronta. Descriptor semi universal de la mujer monstruo agregaría Suazo (2018, p.125). Algo habrán hecho por la historia de Chile y La Quintrala de Sabatini, comparten el canal que acogió los proyectos, y por lo tanto comparten algunas cosas más, como por ejemplo el vestuario, específicamente el de la Quintrala. Esta es parte de las razones de por qué la actriz debía tener un símil físico a la Argandoña. Mas, para Acuña y su equipo fue importante alejar al personaje de la natural crueldad de la Argandoña, y convertirla en cambio solo en una mujer, no un mito de los temores masculinos de las épocas pasadas.

\section{Evolución de género}

Sobre Lynch, se hablaba de su belleza. Está descrita así por casi todos los autores que hablan sobre La Quintrala de del Carril, aquí citados, así como por este mismo trabajo. Sobre del Carril también se habla sobre su apariencia física de galán, y quizás esto es algo común la década de 1950, al star system y la devoción por el actor y la actriz. Sin embargo, a del Carril le siguen adjetivos sobre su talento, tanto como cantante, actor y director, así como por su condición de ídolo popular, incluso sobre su buena pinta. Sobre Lynch, los otros adjetivos varían un poco con respecto al cantor del pueblo. Para Cabrera es "temperamental" y "avasallante", y en la bibliografía incluso se podría extrapolar que un tanto devoradora de hombres, ya que se exponen sus relaciones con del Carril -relación descrita como difícil e inestable-, con el presidente de la Cámara de Diputados y con su marido Hall Bartlett -productor y distribuidor de Columbia Pictures-. Estas características de mujer empoderada son las que su interpretación de la Quintrala utilizó para desarrollar el personaje, y así como le pasase a Argandoña, la fuerza del mito de la Quintrala se le pegó a Lynch. Como sugiere Cabrera "todos los directores de cine se distinguen y definen por el espacial tratamiento que otorgan a la mujer en sus respectivas obras [...] o por la forma en que se las ubica y se las presenta frente al mundo de los hombres" $(1989,76)$. La obra de del Carril le entrega todo el poder a la Quintrala, no uno demoniaco, de hecho, uno de penitencia y duda sobre dios, de deseo y de prohibición. No vemos a Lynch interpretando a una terrateniente, sino a una femme fatale, que no logra seducir al objeto de su deseo -el cura- pero si es seducida y abusada por otros hombres. Esta Quintrala además pierde su agencia en la introducción y conclusión de la obra donde una voz en off juzga divinamente a la Quintrala. Esto es una herencia del mito de Benjamín Vicuña Mackenna, quien somete a Catalina a vivir colgando de un solo cabello sobre el infierno, siendo abrazada por las llamas eternas. La moraleja final para cualquier mujer que se inspire de tanto poder: dios juzga a quienes no son puras de alma y espíritu y tanto deseo, tanta pasión, no son adecuadas para una mujer. 
La Doña y Algo habrán hecho intentaron sacar a relucir distintos aspectos de este personaje, más allá de la mujer arquetípicamente diabólica porque se manda sola: La Doña, explora la libertad sexual y satisfacción de una libido inusitada -que como sugiere Florcita Motuda es algo solo natural-, y Algo habrán hecho explora las capacidades administrativas de las haciendas, necesario para cualquier gran terrateniente y en particular para la Quintrala, quien era dueña de grandes extensiones de tierras y esclavos. Interesante fue la respuesta de algunos medios sobre la hipersexualización de la Quintrala nocturna, que dejaba un poco de lado la brujería y se volvía más libertaria. La Cuarta, periódico de difusión popular, notaba que la diferencia entre las producciones de Sabatini es que La Doña se acerca más al morbo que al temor, como lo hiciese la producción de 1987, "es decir, más al día con la realidad." Esto se explica en la nota diciendo que "nos encontramos con una doña que valora mucho más los ritos sexuales que los satánicos. Algo así como una radiografía de los deseos ocultos de la sociedad actual." Finaliza diciendo: "Porque más que un rol de hace siglos parece un personaje actual jugando con el baúl de la abuela." (Ruiz, 2011).

Efectivamente, en La Doña hay una gran cantidad de parejas, relaciones escondidas, violaciones, y romance, lo que de algún modo obliga a hacer de la Quintrala más que solo una mujer empoderada sexualmente, para poder destacarla de las otras relaciones que entretejen el melodrama, y es aquí donde entra con mucha fuerza el tema del abuso de esclavos -no tratado en ninguna otra serie de una manera tan gráfica- y también el pacto con el diablo, tratado en abundancia - exageradamente se podría añadir- en la versión anterior de Sabatini. En cambio, la Quintrala de Algo habrán hecho por la historia de Chile es consciente de su poder económico. Amenaza al sacerdote que va a rogar por los feligreses, con quitarle el dinero con que se mantiene la iglesia de Santiago. Incluso como publicidad previa al comienzo de la serie, se creó una intervención urbana en la Plaza de Armas un miércoles a la hora de almuerzo, cuando el centro de la ciudad bulle, donde entraron los actores vestidos de época y recrearon una subasta de esclavos; la protagonista fue Basuri. Incluso el aspecto esclavista está visto desde las habilidades de negociación (Gordon, 2010). El personaje en la serie habla de fechas de cosechas, de necesidad de cuerpos de trabajo en los campos y más allá del personaje, la serie misma hace el énfasis en pensarla como múltiples transgresiones para la época: mujer, mestiza, independiente, rica y poderosa, lo que generó el folklore en torno a endemonizarla, ya que, en la época de la inquisición, esto era quizás lo único que pondría en peligro su imperio.

De este modo, las representaciones televisivas de las Quintralas podrían entenderse como una continuación de la obra de Vicuña Mackenna por varias razones. Los Lisperguer y la Quintrala, fue publicado por capítulos junto a un periódico de la época. La fama del mito, la promesa de racional historiografía del siglo XIX, la serialización de la lectura, ayudaron a que tuvieran una gran fama. Eventualmente la visión misógena y racista del autor -propia de su época- contribuyeron a sustentar racionalmente el mito oral. Con las series de televisión, la visualidad del mito y su serialización en la comodidad del hogar, cautiva hoy igual que en el siglo XIX. Cuando digo hoy, es importante destacar que tanto La Quintrala de la dictadura, como La Doña y la educacional son vueltas a poner en pantalla constantemente. Programas de no ficción, como competencias de canto, La hermandad, o panelistas en el mundo de la farándula hablan constantemente del personaje y por lo tanto opera un régimen de repetición (Kompare, 2006). Es decir, en distintos horarios y por 
tiempos sin restricción, el personaje vuelve a la vida. Incluso la obra de del Carril, que se creía perdida, aparece también en la pantalla chica trasandina. De este modo, visibiliza el patrimonio televisivo, dándole valor a las propias creaciones y además creando formas de conmemoración en código visual de género, las cuales apoyan una vertiente de memoria e historia pública.

En muchos de estos audiovisuales, el pasado está tan mitificado como la Quintrala misma, es un pasado violento, de guerra y represión, de inquisición y lucha por el poder. Más la representación de este ha tendido a un oscurantismo medieval, donde se destaca lo desconocido, lo oculto, lo religioso, lo soberano. Sin embargo, la versión de la mujer en cada formato y en cada género es bastante distinta, siempre Catalina de los Ríos y Lisperberg es de la clase alta y a quienes tortura y reprime son personas en servicio. Es su privilegio de clase lo que le posibilita -en términos históricos- no enfrentar a la justicia. Las interpretaciones de la Quintrala en dictadura, con la Argandoña y Maldonado, continúan en parte esta noción de clase alta, impune, que ejerce la violencia. En Argentina la Quintrala también sirvió para verter el problema social de la época, como la crisis con la Iglesia Católica, y es que, como arquetipo monstruoso, devoradora de hombre y de moral, lasciva y libidinosa, desmesurada y amenazante, será el chivo expiatorio del mal del momento. Como propone Sarabia, la Quintrala es "cuerpo de mujer convertido en texto mestizo de discurso legendario e histórico" y "ha estado sujeta a constantes reconstrucciones y cambios a través de los siglos" (Sarabia, 2000, p. 38). Le tememos y nos fascina, respuesta común a lo monstruoso. El audiovisual nos entregó más capital cultural-visual-imaginado del mito, fascina y a ratos produce rechazo, pero todo se ha adecuado a los tiempos presentes. Quizás ya sea hora no solo de revindicar a la mujer que produjo tanto miedo, que generó el mito que asustase a mujeres por generaciones y las mantuviera domadas, quizás debemos esperar a una nueva obra audiovisual que tome como positivas algunas de esas cualidades de independencia que han sido menoscabadas, acorde a esta cuarta ola del feminismo, quizás solo debemos analizarlas fuera del monstruo y en vez desde la agencia de Catalina.

\section{Notas}

1. Esta investigación se realizó gracias al programa de Postdoctorados de Fondecyt, Chile, Folio 3150632.

2. El historiador César Maranghello describe que la actriz consiguió los fondos ya que había establecido una relación afectiva con el presidente de la Cámara de Diputados, doctor Antonio Benítez, quien le hubiese prometido fondos para realizar una obra que la ayudase a demostrar toda su belleza y talento (2000, pp. 601-602, En Paladino 2006, p. 75).

3. Este presupuesto estuvo abocado a los intricados decorados -a cargo de Juan Romero-, la grandilocuente reconstrucción del Santiago colonial -a cargo de Gori Muñoz, recurrente colaborador de del Carril-, además de alrededor de quince detallados vestidos que utiliza la protagonista, costando cada uno veinte mil pesos -vestuario a cargo de Jorge de las Longas- (Gacetilla de Cinematográfica Cinco, citado en Paladino 2006, 76).

4. Vilar recibió el Cóndor de Plata al mejor actor por su interpretación. 
5. Del Carril opinaba: "Estoy convencido que el artista está obligado a pronunciarse políticamente, en especial si sigue una corriente popular, como la gente de cine, la radio, la televisión y lógicamente el teatro, porque si todos ellos no están del lado del pueblo, ¿quién lo va a estar? Cuando un artista llega a un determinado nivel de fama, contrae la obligación de jugarse por toda esa gente que lo ha llevado al éxito, es decir el pueblo al que dirige su mensaje" (Cabrera 1989, p. 18).

6. En un retraso no político, una tormenta destruyó varios de los decorados en diciembre de 1953 (Paladino, 2003, p. 77).

7. La Quintrala recibió el Cóndor de Plata, de la Asociación de Cronistas Cinematográficos de la Argentina en 1956.

8. Fue estrenada en cines Ocean, Grand Palace y Gaumont. A fines de junio la película fue retirada de cartelera por el gobierno. Esto implicó problemas económicos para solventar la cinta. "Un desastre financiero para los productores" (Cabrera 1989, p. 32).

9. Los Lisperguer y la Quintrala: episodio histórico-social con numerosos documentos inéditos, Valparaíso: Impr. del Mercurio, 1877, de Vicuña Mackenna y de Magdalena Petit, la novela titulada La Quintrala, (Santiago: Zig-Zag, 1932).

10. Trabajó en la edición central del noticiero entre marzo 1979 y enero 1982. Según Patricia Guzmán, jefa de prensa de TVN en 1980, su presencia "atraía unos ocho puntos de audiencia. Los hombres la miraban para ver lo buenamoza que estaba y las mujeres, para criticarla o copiarle el escote" (Emol.cl s.f).

11. Quizás por esto mismo, hizo sentido que animara los realities 1810 -y su sucesor 1910(ambos 2009, Canal 13) sobre la vida en cada período histórico, en el marco de las celebraciones Bicentenario de la televisión.

12. Extendiendo su apoyo a los cómplices civiles de la dictadura, representa al partido de derecha Renovación Nacional como concejal y alcaldesa a principios de los 2000.

13. En el programa se intenta dar explicaciones sobre la Quintrala más allá de las leyendas. Por ejemplo, que el sobrenombre de la Quintrala viene del Quitral, parásito que asfixia a las plantas y tienen grandes flores rojas. Uno de los comentaristas dice, y que esto en verdad es un símbolo de la opresión del tiempo. Dos años antes de nacimiento de este personaje se crea el ejército criollo para luchar contra los Mapuche (La Hermandad, Chilevisión, 2017). Suazo reflexiona que las mujeres-monstruo tienden a ejercer una gran atracción sobre quienes creen en lo oculto, la magia y el espiritismo (2018, p.123).

14. Pese al rating de su primera exhibición La Doña se reestreno en el horario de trasnoche (1 AM), en septiembre del 2016, mes en que hay varias conmemoraciones por la independencia de Chile.

15. Sus primeros estudios y profesión fueron en pedagogía y a fines de la década de 1970, entra a estudiar al Conservatorio de música de la Universidad de Chile.

16. Representando a este partido es electo el 2018 como diputado de un distrito de Chile central.

17. En 1982 la canción entra al tercer disco solista de Florcita Motuda "Pollito, sal de tu cascarón y ayuda a otros" (Marchant, 2011). 


\section{Listas de Referencias bibliográficas}

Cabrera, G. (1989). Hugo del Carril, un hombre de nuestro cine, Buenos Aires: Ediciones Culturales Argentinas.

Calzón, M.F. (2016). "Hugo del Carril y su trayectoria como ídolo popular: astro del tango, galán-cantor y director de cine, 1935-1955” en Cuadernos de H Ideas [En línea], vol. 10, no 10, diciembre. En: http://perio.unlp.edu.ar/ojs/index.php/cps/article/view/3476 (Consultado 7 de enero 2019).

Emol.cl (s.f.) "Raquel Argandoña, una domadora” En https://www.emol.com/especiales/ raquel_argandona/raquel.htm (Consultado 28 febrero 2019).

Gordon, F. (2010) "Promoción de serie de TV revoluciona Plaza de Armas con la "Quintrala"” En Publimetro. 15 julio 2010 https://actrizchilena.blogspot.com/2010/07/promocion-deserie-de-tv-revoluciona.html?view=flipcard (Consultado 26 diciembre 2018).

Getionarte, Fundación. (2018). ABCdario actoral II, Santiago; s/e.

Kelly Hopfenblatt, A. y Trombetta, J. (2009) "Características de la censura entre 1933 y 1956. Continuidades y rupturas en la identidad nacional” En Lusnich, A.L. y Piedras, P. (Editores), Una historia del cine político y social en Argentina. Formas, estilos y registros, Volumen I, Buenos Aires: Nueva Librería.

Kriger, C. (2009). Cine y peronismo. El Estado en escena. Buenos Aires. Siglo XXI, pp. 104 y 187.

Kompare, D. (2006) Rerun Nation: How Repeats Invented American Television. New York: Routledge

Letelier, M.B. (2010). "Begoña: la apuesta dramática de TVN interpreta a La Quintrala" Publimetro, 25 julio. En https://web.archive.org/web/20141014131346/http://www. publimetro.cl/nota/espectaculos/begona-la-apuesta-dramatica-de-tvn-interpreta-a-laquintrala/xIQjgy!LxACKZWXY2qRc/ (Consultado 20 diciembre 2018).

Maranghello, C. (1993). Hugo del Carril. Colección Los directores del cine argentino. Buenos Aires: Centro Editor de América Latina.

Marchant, H. (2011). "Tema de La Doña enfrenta a la Maldo con María Jimena" La Cuarta, 26 septiembre. En: https://www.lacuarta.com/espectacular/noticia/tema-de-la-donaenfrenta-a-la-maldo-con-maria-jimena/119695/ (Consultado 1 marzo 2019).

Músicapopular.cl Enciclopedia de la música chilena. http://www.musicapopular.cl/artista/ florcita-motuda/ (Consultado 27 enero 2019).

Paladino, D., (2003). "La Quintrala (Doña Catalina de los Ríos y Lisperguer): una superproducción en el momento equivocado" en Maranghello, C. e Insaurralde, A., Hugo del Carril. El compromiso y la acción, Buenos Aires: Museo del cine.

Ruz, J. (2011). “La Doña, la nueva Xica da Silva de Chilevisión” La Cuarta, 14 octubre. En: https://www.lacuarta.com/sin-categoria/noticia/la-dona-la-nueva-xica-da-silva-dechilevision/49789/ (Consultado 25 enero 2019).

Sarabia, R. (2000) “Doña Catalina De Los Ríos y Lisperguer y la construcción del monstruo Quintrala." En: Anales de Literatura Chilena. Año 1, diciembre 2000, Número 1, 35-52.

Suazo, R. (2018) Víboras, putas, brujas. Una historia de la demonización de la mujer desde Eva hasta la Quintrala. Santiago: Editorial Planeta. 


\begin{abstract}
This article analyses the different representations of women in colonial Chile, specifically the case study of Catalina de los Ríos y Lisperberg, a real-life historical character, who became the archetypical myth of the monster woman, under the nickname of La Quintrala. The article explores the Argentinian film La Quintrala (1955), directed by the popular idol Hugo del Carril. The Chilean television miniseries directed by Vicente Sabatini, La Quintrala, screened though Televisión Nacional de Chile channel (TVN, National Film Television) on air though April and July 1987, during Pinochet's dictatorship. The episode of an educational program Algo habrán hecho por la historia de Chile, directed by Nicolás Acuña, also shown in TVN in June 2010, entitled "El mestizaje, la Quintrala y el poder de los jesuitas (1557 - 1721)". And La Doña, nigh series (erotic series) also directed by Sabatini, thought Chilevisión channel on October 2011. Though these representations it becomes possible to analyse the representations of the colonial past as well as the women who inhabited it, proposing a new interpretations of the audiovisual material to make justice of Catalinas memory.
\end{abstract}

Keywords: Audiovisual interpretations - monster woman - Chilean colony

Resumo: Este artigo discute como já representou as mulheres da colônia, tendo especificamente em conta o caso de Catherine dos Rios e Lisperberg personagem histórico real, tornar-se o mito arquetípico da mulher monstro sob a alcunha do Quintrala. O filme argentino La Quintrala (1955), dirigido por Hugo del Carril, será analisado. A minissérie televisiva de Vicente Sabatini, La Quintrala, exibida na Televisão Nacional do Chile (TVN) e transmitida entre abril e julho de 1987, em plena ditadura. O capítulo "A miscigenação, o Quintrala e poder dos Jesuítas (1557 - 1721)" de algo que eles fizeram na história do Chile, dirigido por Nicolas Acuña, estreou em TVN, em Junho de 2010 e La Doña, noite telenovela também Sabatini , estreou no canal de televisão Chilevisión, em outubro de 2011. Através dessas performances, vamos avaliar como o passado foi imaginado e a mulher em cada caso, propondo uma nova interpretação de Catalina.

Palavras chave: Representação audiovisual - mulher-monstro - colônia chilena

[Las traducciones de los abstracts fueron supervisadas por el autor de cada artículo] 